\title{
Dynamic Monitor of CT Scan Within Short Interval in Invasive Pulmonary Aspergillosis for Nonneutropenic Patients
}

\section{Fei Chen}

Key Laboratory of Respiratory Disease of Zhejiang Province,Department of Respiratory and Critical Care Medicine, Second Affiliated Hospital of Zhejiang University School of Medicine, Hangzhou,Zhejiang

Yonghong Zhong

Department of Respiratory Medicine, First People's Hospital of Yuhang District, Hangzhou, Zhejiang

\section{$\mathrm{Na} \mathrm{Li}$}

Key Laboratory of Respiratory Disease of Zhejiang Province,Department of Respiratory and Critical Care Medicine, Second Affiliated Hospital of Zhejiang University School of Medicine, Hangzhou,Zhejiang

\section{Huijie Wang}

Key Laboratory of Respiratory Disease of Zhejiang Province,Department of Respiratory and Critical Care Medicine, Second Affiliated Hospital of Zhejiang University School of Medicine, Hangzhou,Zhejiang

Yanbin Tan

Department of Radiology, Second Affiliated Hospital of Zhejiang University School of Medicine, Hangzhou, Zhejiang

\section{Hao Zhang}

Key Laboratory of Respiratory Disease of Zhejiang Province,Department of Respiratory and Critical Care Medicine, Second Affiliated Hospital of Zhejiang University School of Medicine, Hangzhou,Zhejiang

Wen Hua

Key Laboratory of Respiratory Disease of Zhejiang Province,Department of Respiratory and Critical Care Medicine, Second Affiliated Hospital of Zhejiang University School of Medicine, Hangzhou,Zhejiang

\section{Yanxiong Mao}

Key Laboratory of Respiratory Disease of Zhejiang Province,Department of Respiratory and Critical Care Medicine, Second Affiliated Hospital of Zhejiang University School of Medicine, Hangzhou,Zhejiang

Huaqiong Huang ( $\sim$ zr_hhq@zju.edu.cn )

Key Laboratory of Respiratory Disease of Zhejiang Province, Department of Respiratory and Critical Care Medicine, Second Affiliated Hospital of Zhejiang University School of Medicine, Hangzhou, Zhejiang, China;

\section{Research Article}

Keywords: CT dynamic monitoring, Aggressive pulmonary aspergillosis, Nonneutropenic, Chronic respiratory diseases

Posted Date: January 18th, 2021

DOI: https://doi.org/10.21203/rs.3.rs-145899/v1

License: (1) (7) This work is licensed under a Creative Commons Attribution 4.0 International License. Read Full License 


\section{Abstract}

Background: In nonneutropenic patients with underlying respiratory diseases (URD), invasive pulmonary aspergillosis (IPA) is a life-threatening disease. Yet establishing early diagnosis in those patients remains quite a challenge.

Methods :A retrospective series of nonneutropenic patients with probable or proven IPA were reviewed from January 2014 to May 2018 in Department of Respiratory Medicine of two Chinese hospitals. Refer to the relevant diagnostic criteria in the $\square$ American Society of Infectious Diseases Guidelines for Invasive Aspergillus 2008 ${ }^{1}$. Those patients were suspected of IPA and underwent lung computed tomography (CT) scans twice within 5-21 days. The items required for IPA diagnosis were assessed by their host factors, mycological findings and CT scans according to EORTC/ MSG criteria.

Results: Together with the risk factors, mycological findings and nonspecific radiological signs on first CT, ten patients were suspected of IPA. With the appearance of cavities on second CT scan in following days, all patients met the criteria of probable or possible IPA. Except one patient who refused antifungal treatment, nine patients received timely antifungal treatment and recovered well. One of the nine treated IPA cases was further confirmed by pathology, one was confirmed by biopys.

Conclusions: Dynamic monitor of CT scan provided specific image evidences for IPA diagnosis. This novel finding might provide a noninvasive and efficient strategy in IPA diagnosis with URD.

\section{Introduction}

Invasive fungal infection refers to the fungus that grows and multiplies in the body's tissues, organs and blood after entering the body, causing tissue damage and triggering a series of inflammatory reactions. Environmental molds that are ubiquitous in the air are the main cause of invasive pulmonary aspergillosis (IPA). IPA usually affects immunocompromised individuals such as solid organ transplant recipients and patients with hematological malignancies including hematopoietic stem cell transplant recipients. Some research results show that IPA is associated with significant morbidity and carry a crude mortality rate of up to $30-40 \%$ in some risk groups ${ }^{2,3}$ Aside from those high-risk groups, the incidence of IPA in nonneutropenic patients with underlying respiratory diseases (URD) such as chronic obstructive pulmonary disease (COPD), asthma, lung cancer or autoimmune diseases with pulmonary involvement is increasing ${ }^{4-6}$ Patients with COPD were reported to be most vulnerable for IPA development ${ }^{5,7}$.The mortality of IPA in URD patients has been found to be between $32 \%$ and $100 \%^{7-9}$. Patients with URD have similar symptoms, signs and radiology, which is likely to cause missed or misdiagnosed IPA in clinical diagnosis ${ }^{3-5}$.

Due to the lack of specificity of the clinical manifestations of IPA, early diagnosis is difficult and the treatment effect is poor, so the mortality rate is extremely high. To establish diagnosis of IPA in URD patients without the classic risk factors is usually difficult, although several diagnostic criteria such as EORTC/ MSG Criteria ${ }^{10}$ and Bulpa Criteria had been applied in daily practice ${ }^{11}$. IPA patients with URD usually present severe clinical conditions and poor lung function which make it difficult to obtain sterile lower respiratory tract samples by bronchoscopy. So sterile samples are rarely collected in daily practice, despite they are important for IPA diagnosis. Non-specific symptoms and signs and insufficient accuracy of diagnostic tests delays early identification and timely antifungal treatment, thus leading to an increased physical and psychological burden.

Novel tests for diagnosis of IPA in patients with URD are under development. Next-generation sequencing (NGS), Aspergillus-specific lateral-flow device tests, bioluminescence and small molecule imaging were reported to be helpful in diagnosis of IPA $8,12,13$. However, these novel tests need be verified in large population and the cost of the test are very high. A simple, noninvasive and effective diagnosis method are urgently needed, especially in developing countries.

Here by adopting a strategy of repeated CT scans within a short interval, we identified 10 cases of IPA in nonneutropenic patients. Our data showed that IPA had common imaging signs such as consolidation and tree-in-bud pattern in the early stage, then showed typical IPA signs such as cavitated nodules and halo signs in the following days. Dynamic CT review within a short interval provided more available evidence for EORTC/ MSG criteria. This strategy might be useful in diagnosis of IPA for non-hematologic immunocompromised patients.

\section{Materials And Methods}

We retrospectively assessed patients admitted in Department of Respiratory Medicine of First People Hospital of Yuhang and Second Affiliated Hospital of Zhejiang University School of Medicine respectively, between Jan 2014 and May 2018. The EORTC/ MSG criteria ${ }^{10}$ was taken as IPA diagnostic criteria (Table 1). We added URD history as host factor according to the previous study ${ }^{14}$. Patients were classified into proven, probable or possible IPA based on host factors \clinical data, mycological criteria, histopathological or cytopathological examination. Details as follows:

a. Possible cases required host factors and clinical data but without Aspergillus isolation or serology. Written informed consent was obtained from each patient.

b. Probable cases require host factors, clinical data (meet one of the followings in CT: dense and well-circumscribed lesion with or without a halo sign, an air-crescent sign or a cavity), and microbiological factors (isolation of Aspergillus in LRT samples, or positive serum or bronchoalveolar lavage fluid Galactomannan test (GM tests).

c. Proven IPA identification require histopathological or cytopathological examination of lung tissue showing Aspergillus hyphae from needle aspiration or biopsy specimen with evidence of associated tissue damage, or positive culture for Aspergillus from a sample obtained by sterile procedure from the lung. 
This study was approved by institutional review board of both hospitals. All procedures performed in studies involving human participants were in accordance with the Helsinki Declaration. Written informed consent was obtained from the patient.

\section{Results}

Ten patients were diagnosed as uncertain IPA at first when they showed poor response to broad antibiotic and/or system corticosteroid (Table 2).

Table 2 is the basic information of the patients. Gender: 8 males and 2 females; Reasons for admission: 1 patient with AECOPD, 2 patients with acute exacerbation of asthma, 7 patients with pneumonia; previous medical history: 1 patient with history of esophageal cancer, 1 patient with history of prostate cancer, 1 patient with herpes zoster infection (relapse 2 months before admission); comorbidities: 1 patients with coronary heart disease, 5 patients with hypertension, and diabetes mellitus (DM) 4 cases, 2 patients with COPD. There were 6 patients with smoking history. The rest had no history of malignant tumors, hematological malignancy or long-term use of immunosuppressive agents. None of the patients had rheumatoid arthritis treated with corticosteroids or immunosuppressive agents, nor had prostate cancer and esophageal cancer after chemotherapy.

The physical examination results show: All patients had cough and sputum, eight patients had wheezing symptoms, some of them had thick wet rales, 4 patients had dyspnea, and 5 patients had body temperature between $37.5^{\circ} \mathrm{C}$ and $39.1^{\circ} \mathrm{C}$. All patients had poor response to broad-spectrum antibiotic and/or corticosteroids. Two of them were admitted to the ICU.

Sputum culture was ordered for once at least and six times at most before initiation of antifungal therapy. Sputum culture results show: Three patient's sputum culture revealed Aspergillus once or twice. One patient's sputum sample reported filamentous fungi in all six sputum samples. Six patients' culture did not reveal Aspergillus at all. In addition $\bowtie$ four patients had a positive galactomannan (GM) test in blood. No patient underwent bronchoscope to obtain lower respiratory tracts samples.

CT scan results show: All ten patients underwent chest CT scan twice. A radiologist was invited to review the first CT signs in a single-blind way (Table 3). At the first CT scan, patients showed common signs of inflammation, like scattered peribronchial consolidations, thickening of bilateral lung texture, small nodular lesions along the bronchial tree, and the 'tree-in bud' pattern. Second lung CT scans were ordered at short intervals of 5-22 days (averaging 9.7 days). All patients had deterioration of lesions with several nodules and cavities. The changes of lung CT in 3 patients are shown in the figure 1 . The intervals of CT scan were 5,8 and 10 days in three cases respectively.

Diagnosis results: visualized by images, majority of walls of cavities were thin. One patient had pleural wedge shape, and one developed pneumothorax. With the typical CT signs of IPA such as cavitied nodular and halo signs appearing on second CT scan, eight patients met the criteria of probable IPA, and two patients met the criteria of the possible IPA (Table 4). Only one patient had large peripheral nodules which allowed a biopsy through CT guidance. The lung tissue revealed Aspergillus (Figure 2).

Treatment process and results (Table 4): Eight of the nine patients were treated with voriconazole for 15 days to 6 months. One patient was treated with voriconazole at first, but had no response. So eight days later the patient was treated with posazonazole instead and had good response. Among the nine patients who received treatment, eight of them recovered well through evaluation of symptoms and CT scan signs and survived, the survival rate was $88.89 \%$. One patient recovered after 2 weeks of voriconazole therapy, but voriconazole was discontinued because of economic cost of voriconazole. The patient died after discharge. Only one patient refused antifungal therapy and was lost during following visit.

\section{Discussion}

Data from a German study shows, during the period from 1979 to 1992, the incidence of invasive mycosis increased by about 8 times, and IPA, as the most harmful type and the most fatal type of pulmonary aspergillosis infection, has gradually been paid attention by clinical researchers ${ }^{14}$. Clinically, IPA is generally divided into neutropenia and non-neutropenia. This study mainly discusses the diagnostic methods of IPA patients with non-neutropenia. We found that IPA in nonneutropenic patients showed a specific progressive deterioration in the CT scan in a short interval, which promoted early diagnosis and timely antifungal therapy. The diagnosis of IPA was validated finally by therapeutic response and/or biopsy. Therefore, our findings provide a noninvasive, feasible and effective strategy for early diagnosis of IPA with URD. To the best of our knowledge, the current report is the first to emphasize the diagnostic value of dynamic monitor of CT scans in IPA with URD.

Research data shows that IPA is commonly diagnosed in neutropenic patients, but also could be diagnosed in nonneutropenic patients with URD ${ }^{5,15}$. In our data, all patients had no neutropenia but less severe forms of immunocompromise in lungs. Most of the reasons for their admission are COPD, asthma and pneumonia, complicated with prostate cancer, hospital acquired pneumonia (HAP), and most of them have underlying diseases such as coronary heart disease, hypertension, and diabetes. Some patients have a history of malignant tumors. So we suggest to keep IPA in mind when managing the patients in Department of Respiratory Medicine. URD of those patients could further increase the complexity of Aspergillus diagnosis. First, pulmonary diseases commonly share same symptoms and signs with IPA, such as fever, dyspnea, chest tightness, wheezing and sputum production. And those non-specific symptoms and signs could mask Aspergillus infections. Second, corticosteroids and broad-spectrum antibiotics are used commonly even overused in these population, which could increase risk for IPA ${ }^{4}, 5$. Third, biomarkers and specific CT signs of IPA are not sensitive in nonneutropenic patients. The specific CT signs like cavity or air crescent are less common in nonneutropenic patients than in neutropenic patients ${ }^{8}$. In agreement with another report ${ }^{16}$, the most common CT finding was consolidation. Such CT signs are non-specific and might correspond to a wide range of morbidities such as bacterial pulmonary infection, cardiac failure, aspiration pneumonia and so on. At last patients' poor clinical conditions like weakness, dyspnea, hypoxic respiratory failure and cardiac failure made invasive procedures such as lung tissue biopsy and bronchoscopy risky. As in our report, only one patient received biopsy. Yet tissue biopsy and lower respiratory tract samples for culture or GM tests in BALF are very specific for IPA ${ }^{10,17 .}$

Page 3/11 
GM is a universal polysaccharide component in the cell wall of Aspergillus, which is a polyantigen. GM appears in circulation about 1 week earlier than clinical symptoms and imaging abnormalities. Continuous monitoring of patients' serum GM levels is helpful for early diagnosis of IPA and timely medication. And the detection of the GM antigen in BALF and serum serves as a reliable assay for the diagnosis of IPA ${ }^{16}$. Positive GM test has been taken as an important criterion for the diagnosis of IPA both by the EORTC/MSG and Bulpa criteria. In our report, only four out of nine patients reported positive GM test. So our results showed that GM assay have relatively low sensitivity in nonneutropenic patients, as reported previously ${ }^{18,19}$. Meanwhile, there were other factors affecting result of GM. One of the GM positive patients had been administered piperacillin-tazobactam prior to the test, which was reported to be one of the reasons for false positives in the serum-GM assay ${ }^{20,21}$.Some studies have reported that the BALF-GM assay is more sensitive than the serum-GM assay and fungal cultures ${ }^{18,20,22}$. This is a shortcoming that BAL procedure was not conducted through bronchoscope as common in our study. A number of reasons prevented doctors to successfully obtain BALF. First, the bad general condition of patients, extreme discomfort and side effects of bronchoscope reduced patients' compliance. Second proper standardization techniques of BAL procedure are still lacking. There were variations in the BALF volumes and GM cut-off values reported in different studies. At last the yield of BALF-GM is associated with the lavage site. Therefore, how to accurately locate the lesion is critical yet very difficult.

Previously studies reported that some special signs in CT are highly suggestive of IPA, like cavity, vessel occlusion signs ${ }^{23}$, patchiness ${ }^{24}$, airway-invasive features in nonneutropenic cases ${ }^{25}$. But several papers have reported that CT signs in nonneutropenic IPA is nonspecific. So the imaging findings of nonneutropenic IPA need further study.

First, it is reported that IPA in nonneutropenic patients have different tissue injury pathogenesis compared with neutropenic patients. Berenguer et al reported that nonneutropenic immunocompromised animals revealed a pattern of inflammatory necrosis but no significant angioinvasion, hemorrhage or infarction histologically demonstrated in persistently neutropenic animals with IPA ${ }^{26}$. The same tissue injury pattern was found in IPA patients ${ }^{27}$. It means the nonneutropenic patients should have the corresponding CT scans of tissue necrosis like cavities or halo signs.

Secondly, given IPA was an infectious disease, it might evolve over several phases which might begin with colonization, progress to infection and, finally lead to manifestation of disease symptoms in patients ${ }^{28}$. This phase evolving was reported in a female case of invasive tracheobronchial Aspergillosis, in which the CT scan was order on day 1 , day 4, day 7, day 21, day 63 and day 139. It was found that invasive tracheobronchial Aspergillosis could progress to IPA with extended parenchymal lesions within a short period ${ }^{29}$. In summary, the CT signs in nonneutropenic IPA might change over time, and specific signs could appear in one certain time point. As showed in our report, IPA underwent a progress beginning with nonspecific CT signs, then developing to cavities within a short period of about 9 days, which was reported as appearing 2 weeks in neutropenic IPA ${ }^{30}$. Until now, this is the first report about the progress deterioration of CT scans in nonneutropenic IPA, the exact dynamic changes of CT scans in nonneutropenic IPA is far from clear, so specific study designed to observe CT signs at different stages of IPA is warranted.

Right now there are several guidelines of diagnosis and treatment for IPA released by several committees, namely EORTC/ MSG criteria ${ }^{10}$, Bulpa criteria ${ }^{31}$ and intensive care unit (ICU) criteria $^{31}$ [32].The scope for each guideline are different. EORTC/ MSG criteria is limited for cancer patients but are also widely used in other patients. The Bulpa criteria is proposed to diagnose IPA specifically in COPD patients. The ICU criteria are proposed to diagnose IPA in the ICU setting. Items required for proven IPA are the same in the three sets of criteria, yet the items required for probable IPA are different. Here we used EORTC/ MSG criteria to diagnose IPA. When patients had a history of severe COPD, Bulpa criteria were also used. As we found, EORTC/ MSG criteria has strict requirements regarding the typical CT findings. So according to EORTC/ MSG criteria, probable/putative IPA should meet one of three CT signs in clinical data as follows, a). Dense, well-circumscribed lesion(s) with or without a halo sign. b) An air-crescent sign. c) A cavity. Yet those typical CT signs for IPA (e.g. halo or aircrescent sign) are particularly rare in early stages in nonneutropenic patient. As showed in our study, the first CT scan only had some nonspecific CT signs as reported before ${ }^{3,9,32}$, which were not helpful for early diagnosis and timely treatment.

Meanwhile, we found there was no requirement for dynamic changes of clinical exacerbation, neither the CT scan nor mycological findings in the EORTC/ MSG criteria. We speculated that it was because of EORTC/ MSG criteria mainly serving for cancer or hematopoietic malignancies, which might deteriorate in hours and days. Yet in IPA in nonneutropenic patients with local airway impaired immunity, the clinical process is not usually so urgent.

Nousheen and colleagues reported the average length of hospital stay were $10.61 \pm 9.08$ days ${ }^{33}$, and ours were 45.3 days. We found there was a very significant CT sign deterioration among those patients after average intervals of 9 days, at least 5 days. Our results suggested that EORTC/ MSG criteria were not sensitive enough for nonneutropenic IPA without reexamination of CT scans. Thus, the procedure of applying dynamic monitor of clinical or dynamic CT scans is a way to optimize the EORTC/ MSG criteria.

\section{Conclusions}

IPA in nonneutropenic patients with URD has become a challenge in clinical practice. By dynamically monitoring disease progression via CT, it might improve the accuracy of diagnosis, especially in seriously-ill patients who could not stand bronchoscopy and lacking positive mycological findings. We suggest the interval of CT scans could be around a week, or at least 5 days in emergency situation based on our data. Our novel finding might provide a valuable noninvasive and efficacious strategy in nonneutropenic IPA.

\section{Abbreviations}

URD : Underlying Respiratory Diseases

IPA : Invasive Pulmonary Aspergillosis 
COPD :Chronic Obstructive Pulmonary Disease

LRTs: Lower Respiratory Tracts

GM tests : Galactomannan test

BALF: Bronchoalveolar Lavage Fluid

AECOPD: Acute Exacerbation of Chronic Obstructive Pulmonary Disease

MP: Methylprednisolone

HAP: Hospital Acquired Pneumonia

\section{Declarations}

AcknowledgementsロWe thank Li Yan, Chen Qingqing, Xu Wucheng for their excellent assistance in patient's treatment.

FundingDThe National Key R\&D Program of China [2017YFC1310604] ,Natural Science Foundation of Zhejiang Province[NO.LQ18H010002]

Availability of data and materials!The datasets generated and/or analysed during the current study are not publicly available due other manuscripts will be published from this data, but are available from the corresponding author on reasonable request.

Ethics approval and consent to participatelThe study was approved by the Ethics Committee for Human Research of the Second Affiliated Hospital of Zhejiang University School of Medicine. Informed consent was obtained for experimentation with human subjects.

Competing interestsロThe authors declare no conflict of interest.

Consent for publication[Not applicable

Authors' contributions $\mathrm{H} H \mathrm{QH}, \mathrm{YXM}$ and $\mathrm{NL}$ designed the study. FC, $\mathrm{YHZ}$ and HJW performed the study and collected data. WH, HZ, YBT analyzed the data. HQH, $\mathrm{YHZ}, \mathrm{FC}$ wrote the paper. All authors critically reviewed the paper and approved it.

\section{Author details:}

${ }^{1}$ Key Laboratory of Respiratory Disease of Zhejiang Province, Department of Respiratory and Critical Care Medicine, Second Affiliated Hospital of Zhejiang University School of Medicine, Hangzhou, Zhejiang, China; ${ }^{2}$ Department of Respiratory Medicine, First People's Hospital of Yuhang District, Hangzhou, Zhejiang, China; ${ }^{3}$ Department of Radiology, Second Affiliated Hospital of Zhejiang University School of Medicine, Hangzhou, Zhejiang, China

\section{References}

1. Walsh, T. J.; Anaissie, E. J.; Denning, D. W.; Herbrecht, R.; Kontoyiannis, D. P.; Marr, K. A.; Morrison, V. A.; Segal, B. H.; Steinbach, W. J.; Stevens, D. A.; van Burik, J. A.; Wingard, J. R.; Patterson, T. F., Treatment of aspergillosis: clinical practice guidelines of the Infectious Diseases Society of America. Clinical infectious diseases: an official publication of the Infectious Diseases Society of America 2008, 46 (3), 327-60.

2. Bitar, D.; Lortholary, O.; Le Strat, Y.; Nicolau, J.; Coignard, B.; Tattevin, P.; Che, D.; Dromer, F., Population-based analysis of invasive fungal infections, France, 2001-2010. Emerging infectious diseases 2014, 20 (7), 1149-55.

3. Baddley, J. W.; Andes, D. R.; Marr, K. A.; Kontoyiannis, D. P.; Alexander, B. D.; Kauffman, C. A.; Oster, R. A.; Anaissie, E. J.; Walsh, T. J.; Schuster, M. G.; Wingard, J. R.; Patterson, T. F.; Ito, J. I.; Williams, O. D.; Chiller, T.; Pappas, P. G., Factors associated with mortality in transplant patients with invasive aspergillosis. Clinical infectious diseases: an official publication of the Infectious Diseases Society of America 2010, 50 (12), $1559-67$.

4. Cornillet, A.; Camus, C.; Nimubona, S.; Gandemer, V.; Tattevin, P.; Belleguic, C.; Chevrier, S.; Meunier, C.; Lebert, C.; Aupée, M.; Caulet-Maugendre, S.; Faucheux, M.; Lelong, B.; Leray, E.; Guiguen, C.; Gangneux, J. P., Comparison of epidemiological, clinical, and biological features of invasive aspergillosis in neutropenic and nonneutropenic patients: a 6-year survey. Clinical infectious diseases: an official publication of the Infectious Diseases Society of America 2006, 43 (5), 577-84.

5. Guinea, J.; Torres-Narbona, M.; Gijón, P.; Muñoz, P.; Pozo, F.; Peláez, T.; de Miguel, J.; Bouza, E., Pulmonary aspergillosis in patients with chronic obstructive pulmonary disease: incidence, risk factors, and outcome. Clinical microbiology and infection: the official publication of the European Society of Clinical Microbiology and Infectious Diseases 2010, 16 (7), 870-7.

6. Yan, X.; Li, M.; Jiang, M.; Zou, L. Q.; Luo, F.; Jiang, Y., Clinical characteristics of 45 patients with invasive pulmonary aspergillosis: retrospective analysis of 1711 lung cancer cases. Cancer 2009, $115(21)$, 5018-25.

7. Ader, F.; Nseir, S.; Le Berre, R.; Leroy, S.; Tillie-Leblond, I.; Marquette, C. H.; Durocher, A., Invasive pulmonary aspergillosis in chronic obstructive pulmonary disease: an emerging fungal pathogen. Clinical microbiology and infection: the official publication of the European Society of Clinical Microbiology and Infectious Diseases 2005, 11 (6), 427-9.

8. Prattes, J.; Flick, H.; Prüller, F.; Koidl, C.; Raggam, R. B.; Palfner, M.; Eigl, S.; Buzina, W.; Zollner-Schwetz, I.; Thornton, C. R.; Krause, R.; Hoenigl, M., Novel tests for diagnosis of invasive aspergillosis in patients with underlying respiratory diseases. American journal of respiratory and critical care medicine 2014, $190(8), 922-9$. 
9. Samarakoon, P.; Soubani, A., Invasive pulmonary aspergillosis in patients with COPD: a report of five cases and systematic review of the literature. Chronic respiratory disease $2008,5(1), 19-27$.

10. De Pauw, B.; Walsh, T. J.; Donnelly, J. P.; Stevens, D. A.; Edwards, J. E.; Calandra, T.; Pappas, P. G.; Maertens, J.; Lortholary, O.; Kauffman, C. A.; Denning, D. W.; Patterson, T. F.; Maschmeyer, G.; Bille, J.; Dismukes, W. E.; Herbrecht, R.; Hope, W. W.; Kibbler, C. C.; Kullberg, B. J.; Marr, K. A.; Muñoz, P.; Odds, F. C.; Perfect, J. R.; Restrepo, A.; Ruhnke, M.; Segal, B. H.; Sobel, J. D.; Sorrell, T. C.; Viscoli, C.; Wingard, J. R.; Zaoutis, T.; Bennett, J. E., Revised definitions of invasive fungal disease from the European Organization for Research and Treatment of Cancer/Invasive Fungal Infections Cooperative Group and the National Institute of Allergy and Infectious Diseases Mycoses Study Group (EORTC/MSG) Consensus Group. Clinical infectious diseases: an official publication of the Infectious Diseases Society of America 2008, 46 (12), 1813-21.

11. Bulpa, P.; Dive, A.; Sibille, Y., Invasive pulmonary aspergillosis in patients with chronic obstructive pulmonary disease. The European respiratory journal 2007, 30 (4), 782-800.

12. Brock, M., Application of bioluminescence imaging for in vivo monitoring of fungal infections. International journal of microbiology $2012,2012,956794$.

13. Yang, Z.; Kontoyiannis, D. P.; Wen, X.; Xiong, C.; Zhang, R.; Albert, N. D.; Li, C., Gamma scintigraphy imaging of murine invasive pulmonary aspergillosis with a (111)In-labeled cyclic peptide. Nuclear medicine and biology 2009, 36 (3), 259-66.

14. Groll, A. H.; Shah, P. M.; Mentzel, C.; Schneider, M.; Just-Nuebling, G.; Huebner, K., Trends in the post-mortem epidemiology of invasive fungal infections at a university hospital. The Journal of infection 1996, $33(1), 23-32$.

15. Liang, S.; Jiang, R.; Lu, H. W.; Mao, B.; Li, M. H.; Li, C. W.; Gu, S. Y.; Bai, J. W.; Xu, J. F., Immunity status of invasive pulmonary aspergillosis patients with structural lung diseases in Chinese adults. Journal of thoracic disease 2017, 9 (2), 247-253.

16. Xu, H.; Li, L.; Huang, W. J.; Wang, L. X.; Li, W. F.; Yuan, W. F., Invasive pulmonary aspergillosis in patients with chronic obstructive pulmonary disease: a case control study from China. Clinical microbiology and infection: the official publication of the European Society of Clinical Microbiology and Infectious Diseases 2012, 18 (4), 403-8.

17. Zou, M.; Tang, L.; Zhao, S.; Zhao, Z.; Chen, L.; Chen, P.; Huang, Z.; Li, J.; Chen, L.; Fan, X., Systematic review and meta-analysis of detecting galactomannan in bronchoalveolar lavage fluid for diagnosing invasive aspergillosis. PLoS One 2012, 7 (8), e43347.

18. Dong, X. Q.; Shen, Q.; Yao, Y. N.; Chen, J. J.; Lu, G. H.; Zhou, J. Y., [Determination of biomarkers in exhaled breath condensation of acute exacerbation of chronic obstructive pulmonary disease and its clinical implications]. Zhonghua jie he he hu xi za zhi = Zhonghua jiehe he huxi zazhi =Chinese journal of tuberculosis and respiratory diseases 2017, 40 (2), 114-117.

19. Fortún, J.; Martín-Dávila, P.; Gomez Garcia de la Pedrosa, E.; Silva, J. T.; Garcia-Rodríguez, J.; Benito, D.; Venanzi, E.; Castaño, F.; Fernández-Ruiz, M.; Lazaro, F.; García-Luján, R.; Quiles, I.; Cabanillas, J. J.; Moreno, S.; Aguado, J. M., Galactomannan in bronchoalveolar lavage fluid for diagnosis of invasive aspergillosis in non-hematological patients. The Journal of infection 2016, 72 (6), 738-744.

20. Nguyen, M. H.; Jaber, R.; Leather, H. L.; Wingard, J. R.; Staley, B.; Wheat, L. J.; Cline, C. L.; Baz, M.; Rand, K. H.; Clancy, C. J., Use of bronchoalveolar lavage to detect galactomannan for diagnosis of pulmonary aspergillosis among nonimmunocompromised hosts. Journal of clinical microbiology 2007, 45 (9), 2787-92.

21. Park, S. Y.; Lee, S. O.; Choi, S. H.; Jeong, J. Y.; Sung, H.; Kim, M. N.; Choi, C. M.; Hong, S. B.; Oh, Y. M.; Shim, T. S.; Lim, C. M.; Koh, Y.; Kim, D. S.; Kim, Y. S.; Woo, J. H.; Kim, S. H., Serum and bronchoalveolar lavage fluid galactomannan assays in patients with pulmonary aspergilloma. Clinical infectious diseases: an official publication of the Infectious Diseases Society of America 2011, 52 (7), e149-52.

22. Zhang, S.; Wang, S.; Wan, Z.; Li, R.; Yu, J., The diagnosis of invasive and noninvasive pulmonary aspergillosis by serum and bronchoalveolar lavage fluid galactomannan assay. BioMed research international 2015, 2015, 943691.

23. Henzler, C.; Henzler, T.; Buchheidt, D.; Nance, J. W.; Weis, C. A.; Vogelmann, R.; Benck, U.; Viergutz, T.; Becher, T.; Boch, T.; Klein, S. A.; Heidenreich, D.; Pilz, L.; Meyer, M.; Deckert, P. M.; Hofmann, W. K.; Schoenberg, S. O.; Reinwald, M., Diagnostic Performance of Contrast Enhanced Pulmonary Computed Tomography Angiography for the Detection of Angioinvasive Pulmonary Aspergillosis in Immunocompromised Patients. Scientific reports 2017, 7(1), 4483.

24. Huang, L.; He, H.; Ding, Y.; Jin, J.; Zhan, Q., Values of radiological examinations for the diagnosis and prognosis of invasive bronchial-pulmonary aspergillosis in critically ill patients with chronic obstructive pulmonary diseases. The clinical respiratory journal 2018,12 (2), $499-509$.

25. Jung, J.; Kim, M. Y.; Lee, H. J.; Park, Y. S.; Lee, S. O.; Choi, S. H.; Kim, Y. S.; Woo, J. H.; Kim, S. H., Comparison of computed tomographic findings in pulmonary mucormycosis and invasive pulmonary aspergillosis. Clinical microbiology and infection: the official publication of the European Society of Clinical Microbiology and Infectious Diseases 2015, 21 (7), 684.e11-8.

26. Berenguer, J.; Allende, M. C.; Lee, J. W.; Garrett, K.; Lyman, C.; Ali, N. M.; Bacher, J.; Pizzo, P. A.; Walsh, T. J., Pathogenesis of pulmonary aspergillosis. Granulocytopenia versus cyclosporine and methylprednisolone-induced immunosuppression. American journal of respiratory and critical care medicine 1995, $152(3), 1079-86$.

27. Stergiopoulou, T.; Meletiadis, J.; Roilides, E.; Kleiner, D. E.; Schaufele, R.; Roden, M.; Harrington, S.; Dad, L.; Segal, B.; Walsh, T. J., Host-dependent patterns of tissue injury in invasive pulmonary aspergillosis. American journal of clinical pathology 2007, 127 (3), 349-55.

28. Rogers, T. R.; Slavin, M. A.; Donnelly, J. P., Antifungal prophylaxis during treatment for haematological malignancies: are we there yet? British journal of haematology 2011, $153(6), 681-97$.

29. Ohta, H.; Yamazaki, S.; Miura, Y.; Kanazawa, M.; Sakai, F.; Nagata, M., Invasive tracheobronchial aspergillosis progressing from bronchial to diffuse lung parenchymal lesions. Respirology case reports 2016, 4 (1), 32-4.

30. Prasad, A.; Agarwal, K.; Deepak, D.; Atwal, S. S., Pulmonary Aspergillosis: What CT can Offer Before it is too Late! Journal of clinical and diagnostic research: JCDR 2016, 10 (4), Te01-5. 
31. Blot, S. I.; Taccone, F. S.; Van den Abeele, A. M.; Bulpa, P.; Meersseman, W.; Brusselaers, N.; Dimopoulos, G.; Paiva, J. A.; Misset, B.; Rello, J.; Vandewoude, K.; Vogelaers, D., A clinical algorithm to diagnose invasive pulmonary aspergillosis in critically ill patients. American journal of respiratory and critical care medicine 2012, $186(1), 56-64$.

32. Gotway, M. B.; Dawn, S. K.; Caoili, E. M.; Reddy, G. P.; Araoz, P. A.; Webb, W. R., The radiologic spectrum of pulmonary Aspergillus infections. Journal of computer assisted tomography 2002, 26 (2), 159-73.

33. Iqbal, N.; Irfan, M.; Zubairi, A. B.; Jabeen, K.; Awan, S.; Khan, J. A., Clinical manifestations and outcomes of pulmonary aspergillosis: experience from Pakistan. BMJ open respiratory research 2016, 3 (1), e000155.

\section{Tables}

Table 1. IPA classification according to revised 2008 EORTC/MSG criteria

\begin{tabular}{|c|c|c|c|c|}
\hline \multirow[t]{7}{*}{$\begin{array}{l}\text { EORTC/MSG } \\
\text { Criteria }\end{array}$} & Host factors & Clinical criteria: & Mycological criteria & \multirow{7}{*}{$\begin{array}{l}\text { Histopathological or } \\
\text { cytopathological } \\
\text { examination }\end{array}$} \\
\hline & $\begin{array}{l}\text { i) Recent history of } \\
\text { neutropenia }\end{array}$ & \multirow{2}{*}{$\begin{array}{l}\text { The presence of } 1 \text { of the } \\
\text { following } 3 \text { signs on CT: } \\
\text { i) Dense, well- } \\
\text { circumscribed lesion(s) with or } \\
\text { without a halo sign. }\end{array}$} & \multirow{6}{*}{$\begin{array}{l}\text { i) Positive culture and/or } \\
\text { microscopy result for sputum, BALF, } \\
\text { bronchial brush. } \\
\text { ii) Positive serum or BALF GM } \\
\text { tests. }\end{array}$} & \\
\hline & $\begin{array}{l}\text { ii) Receipt of an } \\
\text { allogeneic stem cell } \\
\text { transplant }\end{array}$ & & & \\
\hline & $\begin{array}{l}\text { iii) Prolonged use of } \\
\text { corticosteroids }\end{array}$ & \multirow{4}{*}{$\begin{array}{l}\text { ii) An air-crescent sign. } \\
\text { iii) A cavity. }\end{array}$} & & \\
\hline & $\begin{array}{l}\text { iv) Treatment with other } \\
\text { recognized T cell } \\
\text { immunosuppressants }\end{array}$ & & & \\
\hline & $\begin{array}{l}\text { v) Inherited severe } \\
\text { immunodeficiency }\end{array}$ & & & \\
\hline & vi) $\quad \mathrm{URD}^{*}$ & & & \\
\hline $\begin{array}{l}\text { Possible } \\
\text { IPA }\end{array}$ & $\sqrt{ }$ & $\sqrt{ }$ & & \\
\hline $\begin{array}{l}\text { Probable } \\
\text { IPA }\end{array}$ & $\sqrt{ }$ & $\sqrt{ }$ & $\sqrt{ }$ & \\
\hline $\begin{array}{l}\text { Proven } \\
\text { IPA }\end{array}$ & & & & $\sqrt{ }$ \\
\hline
\end{tabular}

URD: underlying respiratory diseases. LRTs: lower respiratory tracts. BALF: bronchoalveolar lavage fluid. GM: galactomannan tests.

*, URD was added as host factors in our study according to previous report

Table 2区 Patients' characteristics 


\begin{tabular}{|c|c|c|c|c|c|c|c|c|c|c|}
\hline $\begin{array}{l}\text { Case } \\
\text { No. }\end{array}$ & Sex & Age & $\begin{array}{l}\text { Diagnosis } \\
\text { while } \\
\text { admission }\end{array}$ & Comorbidity & $\begin{array}{l}\text { Smoking } \\
\text { (package/year) }\end{array}$ & $\begin{array}{l}\text { Methylprednisolone } \\
\text { Consumption } \\
\text { before } \\
\text { diagnosis(mg) }\end{array}$ & $\begin{array}{l}\text { Broad } \\
\text { antibiotic } \\
\text { therapy }\end{array}$ & $\begin{array}{l}\text { Neutrophil } \\
\left(\times 10^{9}\right)\end{array}$ & $\begin{array}{l}\text { Sputum } \\
\text { Culture】times[ }\end{array}$ & Sputum C \\
\hline 1 & M & 71 & Pneumonia & $\begin{array}{l}\text { Coronary heart } \\
\text { disease, } \\
\text { Hypertension, } \\
\text { DM,COPD }\end{array}$ & 55 & 253 & Yes & 10.37 & 4 & $\begin{array}{l}\text { Aspergillu } \\
\text { Klebsiella } \\
\text { Normal (tı }\end{array}$ \\
\hline 2 & $M$ & 77 & Pneumonia & $\begin{array}{l}\text { Hypertension, } \\
\text { prostatic } \\
\text { hyperplasia } \rrbracket \\
\text { prostatic cancer }\end{array}$ & $\mathrm{N} / \mathrm{A}$ & 1048 & Yes & 12.22 & 1 & Normal (o \\
\hline 3 & $M$ & 73 & $\begin{array}{l}\text { Acute } \\
\text { exacerbation } \\
\text { of asthma }\end{array}$ & $\begin{array}{l}\text { Hypertension, } \\
\text { DM, } \\
\text { rheumatoid } \\
\text { arthritis }\end{array}$ & 20 & 1040 & Yes & 13.44 & 7 & $\begin{array}{l}\text { Normal } \\
\text { (seven tim }\end{array}$ \\
\hline 4 & $\mathrm{~F}$ & 81 & $\begin{array}{l}\text { Acute } \\
\text { exacerbation } \\
\text { of COPD }\end{array}$ & $\begin{array}{l}\text { Zoster, } \\
\text { schistosomias } \\
\text { liver disease }\end{array}$ & $\mathrm{N} / \mathrm{A}$ & 1032 & Yes & 9.96 & 2 & $\begin{array}{l}\text { Stenotrop } \\
\text { maltophil. } \\
\text { Normal (o }\end{array}$ \\
\hline 5 & $\mathrm{~F}$ & 62 & $\begin{array}{l}\text { Acute } \\
\text { exacerbation } \\
\text { of asthma }\end{array}$ & None & $\mathrm{N} / \mathrm{A}$ & 2360 & Yes & 5.47 & 5 & $\begin{array}{l}\begin{array}{l}\text { Filamentc } \\
\text { (once) }\end{array} \\
\text { Klebsiella } \\
\text { Acinetoba } \\
\text { Bauman ( } \\
\text { Normal(th }\end{array}$ \\
\hline 6 & $M$ & 58 & Pneumonia & $\begin{array}{l}\text { Postoperative } \\
\text { esophagus } \\
\text { cancer }\end{array}$ & 20 & None & Yes & 8.79 & 5 & $\begin{array}{l}\text { Candida a } \\
\text { (twice) } \\
\text { Normal(th }\end{array}$ \\
\hline 7 & M & 84 & Pneumonia & $\begin{array}{l}\text { DM, knee } \\
\text { arthroplasty }\end{array}$ & $\mathrm{N} / \mathrm{A}$ & $1200 \mathrm{mg}$ & Yes & 17.81 & 1 & Aspergillu \\
\hline 8 & $M$ & 64 & Pneumonia & Liver dysfunction & 30 & None & Yes & 9.13 & 3 & $\begin{array}{l}\text { Aspergillu } \\
\text { Normal(or }\end{array}$ \\
\hline 9 & $M$ & 76 & Pneumonia & \begin{tabular}{l} 
Hypertension\} $\\
{\text { Parkinson \COPD }}$ & 15 & None & Yes & 2.52 & 1 & Normal(or \\
\hline 10 & $M$ & 42 & Pneumonia & $\begin{array}{l}\text { Drug - induced } \\
\text { hypersensitivity } \\
\text { syndrome / } \\
\text { Hypertension/DM }\end{array}$ & 20 & $\begin{array}{l}\text { Unclear dosage for } \\
\text { more than } 2 \\
\text { months, }\end{array}$ & Yes & 4.31 & 2 & $\begin{array}{l}\text { Candida á } \\
\text { (twice) } \\
\text { Staphyloc } \\
\text { aureus (or }\end{array}$ \\
\hline
\end{tabular}
\end{tabular}

Table 3: The signs appearing in the initial CT scans 


\begin{tabular}{|c|c|c|c|c|c|c|c|c|}
\hline $\begin{array}{l}\text { Case } \\
\text { No. }\end{array}$ & $\begin{array}{l}\text { Peribronchial } \\
\text { consolidations }\end{array}$ & $\begin{array}{l}\text { Thickening of } \\
\text { bilateral lung texture }\end{array}$ & $\begin{array}{l}\text { The 'tree in } \\
\text { bud' pattern }\end{array}$ & $\begin{array}{l}\text { Big nodular } \\
\text { infiltrates } \\
(\geq 3 \mathrm{~cm})\end{array}$ & $\begin{array}{l}\text { Tiny-small } \\
\text { nodular } \\
\text { infiltrates } \\
(\square 3 \mathrm{~cm})\end{array}$ & $\begin{array}{l}\text { Halo } \\
\text { sign }\end{array}$ & Cavities & $\begin{array}{l}\text { The intervals between initial } \\
\text { and second CT scan (Days) }\end{array}$ \\
\hline 1 & $\sqrt{ }$ & $\sqrt{ }$ & $\sqrt{ }$ & $x$ & $\sqrt{ }$ & $\sqrt{ } *$ & $x$ & 6 \\
\hline 2 & $\sqrt{ }$ & $\sqrt{ }$ & $\sqrt{ }$ & $x$ & $\sqrt{ }$ & $x$ & $x$ & 8 \\
\hline 3 & $\sqrt{ }$ & $\sqrt{ }$ & $\sqrt{ }$ & $x$ & $x$ & $x$ & $x$ & 10 \\
\hline 4 & $\sqrt{ }$ & $\sqrt{ }$ & $\sqrt{ }$ & $x$ & $x$ & $x$ & $x$ & 7 \\
\hline 5 & $\sqrt{ }$ & $\sqrt{ }$ & $\sqrt{ }$ & $x$ & $x$ & $x$ & $x$ & 20 \\
\hline 6 & $\sqrt{ }$ & $\sqrt{ }$ & $\sqrt{ }$ & $x$ & $\sqrt{ }$ & $x$ & $x$ & 5 \\
\hline 7 & $\sqrt{ }$ & $\sqrt{ }$ & $\sqrt{ }$ & $x$ & $x$ & $x$ & $x$ & 5 \\
\hline 8 & $\sqrt{ }$ & $\sqrt{ }$ & $\sqrt{ }$ & $x$ & $\sqrt{ }$ & $\sqrt{ }$ & $x$ & 7 \\
\hline 9 & $x$ & $\sqrt{ }$ & $x$ & $\sqrt{ }$ & $\sqrt{ }$ & $x$ & $x$ & 22 \\
\hline 10 & $\sqrt{ }$ & $\sqrt{ }$ & $\sqrt{ }$ & $x$ & $x$ & $x$ & $x$ & 7 \\
\hline
\end{tabular}

Note: A radiologist was invited to review the patients' CT scans in a single-blind way. " $\sqrt{ }$ ", the sign was found on CT. " $x$ ", didn't found on CT.

*, There was a small nodule( $1.1 \mathrm{~mm} \times 0.9 \mathrm{~mm})$ with halo sign in upper right lung on CT scan.

Table 4ロFinal Diagnosis and outcomes of patients

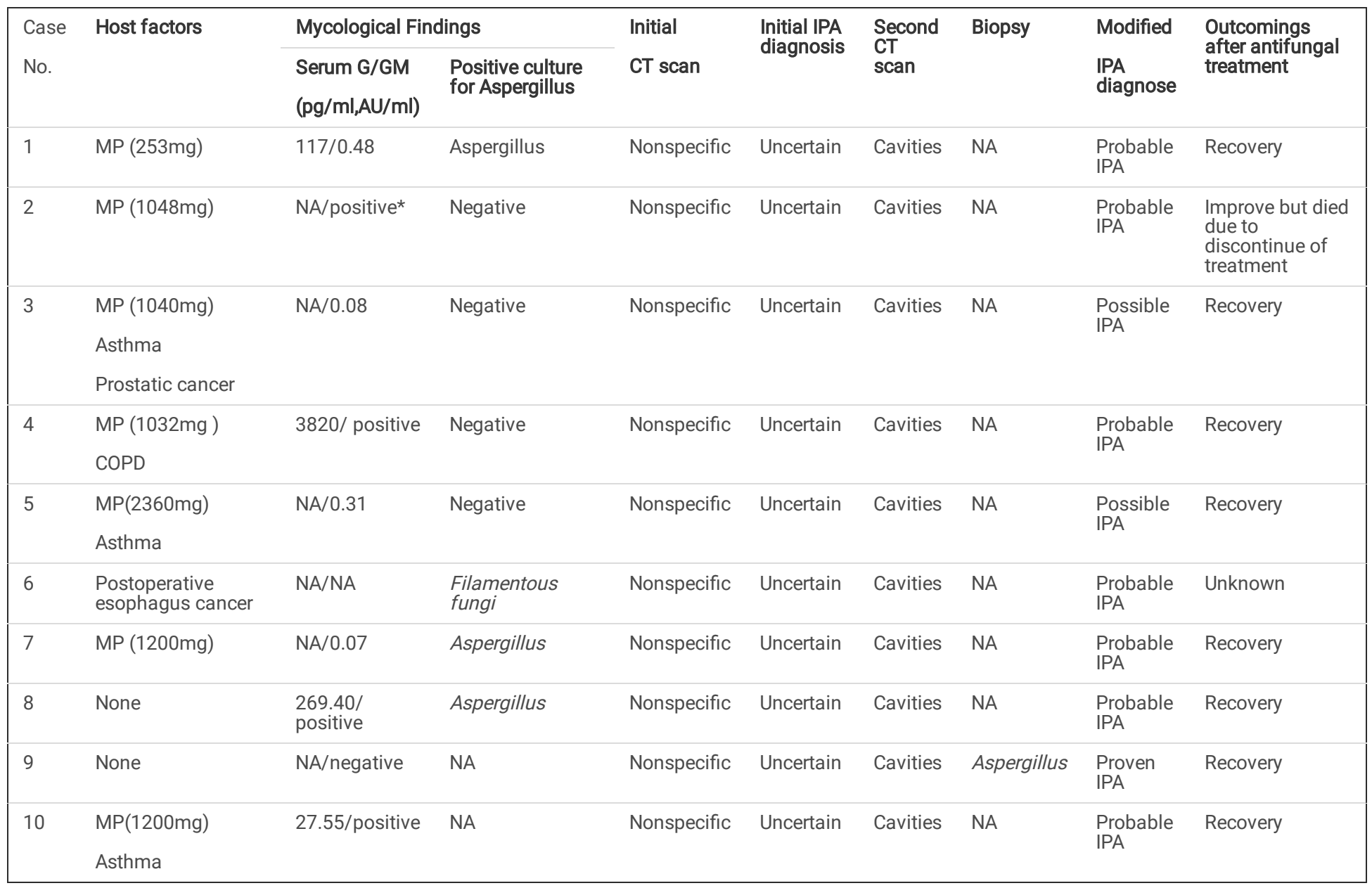

Note: MP: Methylprednisolone. *Before G/GM detection, piperacillin tazobactam was used in this case. NA: not applicable. 


\section{Figures}
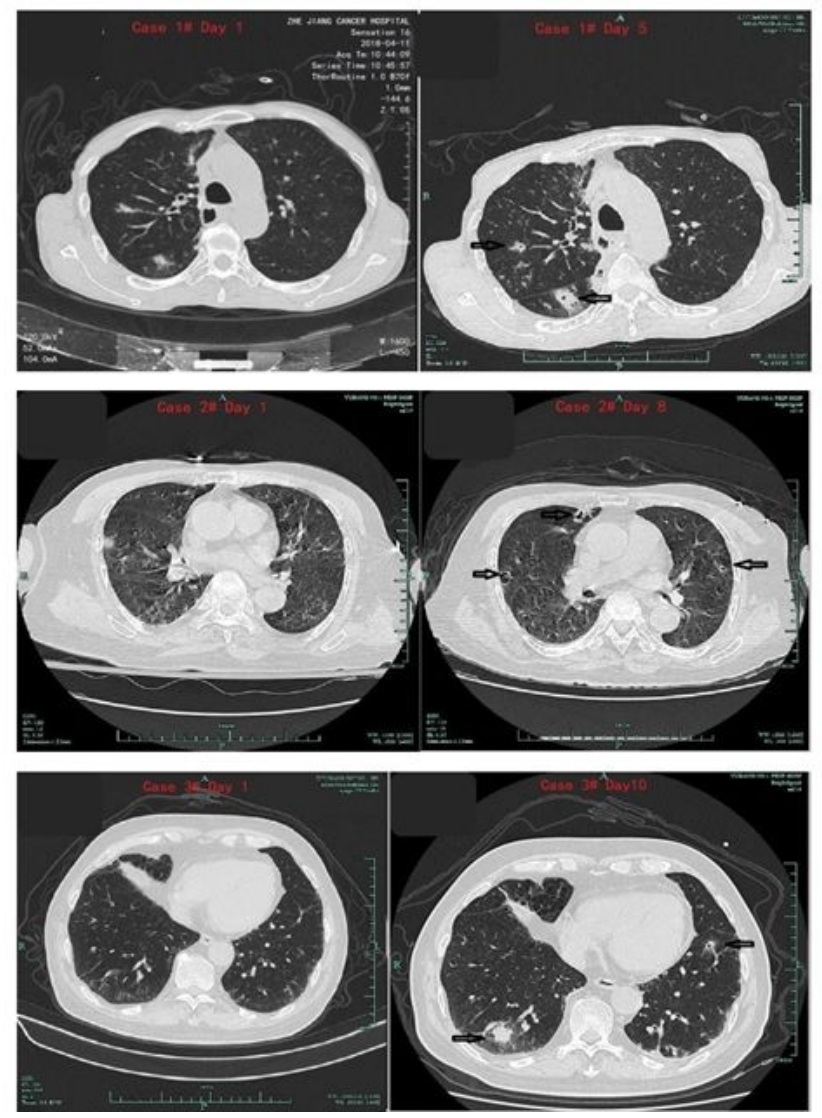

Figure 1

Dynamic monitoring of CT scans at short intervals of 5, 8 and 10 days in three cases respectively. The first CT scan of patients showed
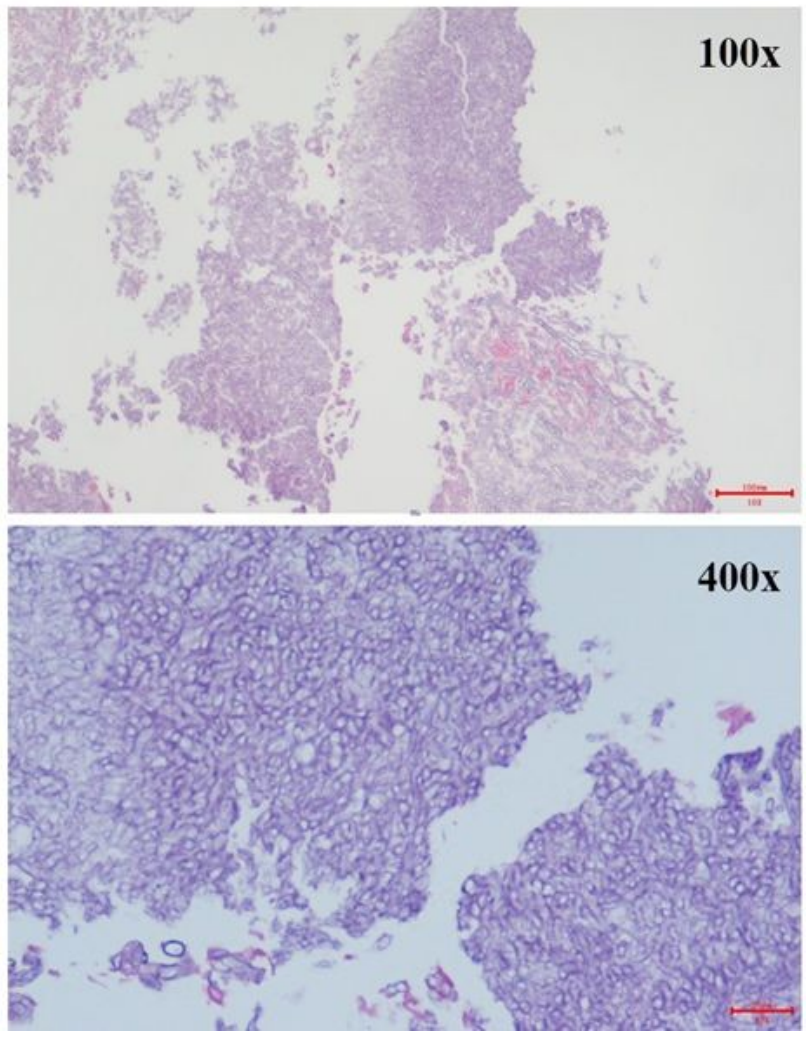

Figure 2 
Detection of Aspergillus in lung biopsy sample of one patient in 100x and 400x magnitude respectively.

Page 11/11 